PROBLEMS

OF EDUCATION

IN THE $21^{\text {st }}$ CENTURY

Volume 61,2014

\title{
46 THE EXAMINATION OF THE IMPACT ON STUDENTS' USE OF GESTURES WHILE WORKING IN A VIRTUAL CHEMICAL LABORATORY FOR THEIR COGNITIVE ABILITIES
}

\author{
Piotr Jagodziński, Robert Wolski \\ Adam Mickiewicz University, Poland \\ E-mail: wola@amu.edu.pl
}

\begin{abstract}
One of the cognitive theories is the embodied cognition theory. According to this theory, it is important to use appropriate gestures in the process of assimilating new information and the acquisition of new skills. The further development of information and communication technologies has enabled the development of interfaces that allow the user to control computer programs and electronic devices by using gestures. These Natural User Interfaces (NUI) were used in teaching Chemistry in middle school and secondary school. A virtual chemical laboratory was developed in which students can simulate the performance of laboratory activities, similar to those that are performed in a real lab. The Kinect sensor was used to detect and analyze hand movement. The conducted research established the educational effectiveness of a virtual laboratory, which is an example of a system based on GBS gestures (gesture-based system). The use of the teaching methods and to what extent they increase the student's complete understanding were examined. The results indicate that the use of the gesture-based system in teaching makes it more attractive and increases the quality of teaching Chemistry.
\end{abstract}

Key words: chemistry experiments, educational simulation, gesture based system, embodied cognition theory.

\section{Introduction}

\section{An Experiment in Teaching Chemistry}

In science classes, students should perform experiments because they are the carriers of basic information in a particular discipline. The equipment in a chemical laboratory and students working methods in experiments are elements of individual work, through which every student can practice basic skills; for example, the techniques of laboratory work (Tatli, 2009). In addition, the laboratory exercises and mental activities related to them, such as reasoning, critical thinking and scientific prediction, that cause an increase in theoretical and laboratory problem-solving (Odubunni \& Balagun, 1991; Ayas, Cepni \& Akdeniz, 1994). This motivates the students to self-critical thinking in designing new experiments and conducting research in the way scientists do. These activities must be guided by the thesis that the knowledge of reality is only effective when it binds with transforming it (Bozdogan \& Yalcın, 2004). 
Piotr JAGODZIŃSKI, Robert WOLSKI. The Examination of the Impact on Students' Use of Gestures while Working in a Virtual Chemical Laboratory for their Cognitive Abilities

The Development of Information and Communication Technology (ICT) and Chemistry Education

The development of information and communication technologies (ICT) has a major impact on education, including the process of teaching-learning (Lamanauskas, 2011; Xie and Reider, 2013). An important issue is the proper implementation of this technology in the educational process in such a way as to be able to support students in developing their skills and knowledge (Zhang, 2013). ICT can help students and teachers broaden their thought horizons and help them towards a better understanding of scientific phenomena and conducting investigations before carrying out scientific research (Lamanauskas, 2011; Ebenezer, 2011, 2012; Calik, 2013; Zhang, 2013). This implies that the ICT tools can be useful to students in inquiring and understanding scientific concepts (Krajcik, 2002; Josephse \& Kosminska, 2006). The authors of the article have already successfully applied ICT technology to support the student's laboratory work by developing a multimedia web script for lab exercises on the subject of Chemistry experiments and by examining its usefulness in teaching Chemistry (Jagodziński \& Wolski, 2012; Chemical experiment, 2008).

\section{Virtual Laboratories in Science Education}

Virtual labs allow working and learning to take place in any place at any time. They leave the school walls and move everything to another part of the environment, making the learning process more dynamic by using a simulation (Yang \&Heh, 2007; de Grove, 2012; Liu and Su, 2011). In virtual labs, students were active, taking part in conducting experiments, working alone or with their colleagues (Dede, Salzman \& Loftin, 1994). Students using virtual laboratories can work according to their pace of learning and personal needs (Sanger, Greenbowe, 2000; Stieff \& Wilensky, 2003; Pekdag, 2010; Machkova \& Bilek, 2013). In a traditional laboratory, work involves dealing with technical problems, complying with safety regulations, costing in association with equipment in addition to the performance of experiments, and reducing the hours devoted to laboratory work. An effective solution to these problems is in using currently available virtual laboratories, which, to some extent, allow experimenting without the restrictions mentioned above (Millar, 2004; Bílek, 2010). The emergence of Natural User Interfaces (NUI) has created new opportunities in controlling simulation programs. This control is done with natural user movements and gestures, making the service more natural and intuitive. It became possible to prepare software, which enables the user to be more involved in practical activities (Svec \& Anderson, 1995).

\section{Embodied Cognition Theories in Chemistry}

There has been an increased interest in alternative presentation models, called "embodied cognition theories", in the last couple of years. According to the theory, human knowledge requires a "re-experience" of an event, using sensual processes that participated in the initial perception of the stimulus (Barsalou, 1999; Wilson, 2002; Prinz, 2002). Behavioral studies suggest that bodily conditions can be the cause of cognitive states and may also be the result of these conditions (Barsalou, 2008; de Koning \& Tabbers, 2011). So, a student mentally processing information in multimedia instructional materials, supported by body motion, causes the activation of brain areas that are responsible for cognitive processes. The inclusion of human movements to this process makes learning while using any multimedia content more effective (Ayres, 2009; Wong, 2009). These conclusions are supported by the magnetic resonance imaging results, which indicated that the cerebral cortex is activated when the transmission of information is supported by appropriate gestures (Macedonia, Müller \& Friderici, 2010). In 
Piotr JAGODZIŃSKI, Robert WOLSKI. The Examination of the Impact on Students' Use of Gestures while Working in a Virtual Chemical Laboratory for their Cognitive Abilities

OF EDU

PROBLEMS

IN THE $21^{\text {st }}$ CENTURY

Volume 61,2014

support of this claim, Johnson (2011) determined that computer gesture recognition is a necessary technology that will have a big impact on education in the near future. Chang (2013) used a Kinect sensor to support the presentation of some multimedia content. They used certain gestures that functioned as wireless hot keys. These gestures were recognized by the Kinect sensor and were used to control PowerPoint presentations. In the studies described above, applying motion sensors in education caused an increase in the effectiveness of learning. This encouraged us to develop a virtual chemical laboratory in which the work is based on the movement and gestures of the user, while being recorded and processed through a Kinect sensor. Virtual chemical laboratories that are currently available only operate on the basis of interfaces such as a keyboard and a mouse. They do not provide the natural user program behavior, such as while working in a real laboratory („Chemistry labs”, n.d.). The use of natural user interfaces (NUI) (Murphy, 2012) creates new opportunities in virtual laboratory design that is based on a gesture-based system.

\section{Research Problem}

Taking into account the reports described above with regard to information and communication technology development and embodied cognition theories, a virtual chemical laboratory was prepared in which the system was used to recognize gestures and movements. The educational experiment was designed to examine how the use of the gesture-based system in a virtual chemical laboratory affects the perceptual abilities of students in the relevant taxonomy category of the teaching goals, i.e., in terms of memorizing information, understanding information, using said information in a typical situation, and in solving problems in the laboratory.

\section{Methodology of Research}

At the beginning, groups of students participating in the study were assembled. In the first stage of the research, the students answered the questions in the pre-test (Cohen, 2011) to determine their initial knowledge level of the subjects, which were included in the research. Next, each group of students began working with their assigned educational means. The first student group worked with the virtual laboratory. There were five posts from the Kinect sensors in the classroom. During one lesson, each student simulated conducting a chemical experiment, working once with the virtual lab. Each student performed a chemical experiment for about 5 minutes. In this way, 5 students finished their experiments in 25 minutes. The second student group worked with films depicting the course of the same Chemistry experiments, which the first group of students worked with. The second group of students was able to see the course experiment only once and the reader discussed only the next steps of the experiment. The third group of students watched the experiments presented by a teacher in the form of a teaching demonstration. The teacher also performed the same experiments, which the students from the first and second groups worked with. During the demonstration, the teacher went through the following steps in the experiments carried out (Table 1).

The students took part in five cycles of classes, differing in themes. One thematic cycle consisted of two lessons. At the beginning of the first lesson, the students acquainted themselves with the theoretical lessons' material, covering a specific topic; for example, the chemical reactions of acids with metals. In the second part of the lesson, the students, representing particular groups, had to learn about the planned experiments, working with an appropriate teaching method or by watching a demonstration by teachers. Following that, the students filled out a card on which they put down their observations of the experiment while formulating appropriate conclusions. In the second lesson, the students compared the results of their work. After completing all the planned class cycles, the students from all the groups answered the 
Piotr JAGODZIŃSKI, Robert WOLSKI. The Examination of the Impact on Students' Use of Gestures while Working in a Virtual Chemical Laboratory for their Cognitive Abilities

post-test questions. The purpose of this test was to determine the final level of the amount of information gained by the students, falling within the scope of the pre-test. After that, the students, who worked with the virtual lab, responded to the survey. The research lasted four months in school year 2012/2013. It simultaneously took place in all the groups. Three months after the termination of the pre-test, the students answered the test questions in the delayed post-test. The purpose of this test was to determine among the students the level of the gained information's durability.

Two teachers were involved in this research. One of them taught all of the middle school student groups, while the other one taught all of the secondary school student groups.

\section{Sample of Research}

Three classes, representing the same middle school and secondary school, took part in the educational research. The study covered students in the second year in both the middle school and the secondary school. In each school, the particular classes represented a separate student research group. The different groups of students were chosen at random. The age of the middle school students from the second year was 14, whereas the age of the secondary school students from the second year was 17 . Table 1 contains the markings of the students with their characteristics.

Table 1. Groups of students, along with their characteristics.

\begin{tabular}{|c|c|c|c|c|}
\hline \multicolumn{2}{|c|}{ Group symbols } & \multicolumn{2}{|c|}{ Students age $\mathrm{e}^{\mathrm{a}}$} & \multirow{3}{*}{$\begin{array}{l}\begin{array}{l}\text { Number } \\
\text { of students }\end{array} \\
\mathrm{N} \\
25\end{array}$} \\
\hline & & \multirow{2}{*}{$\begin{array}{l}\mathbf{M} \\
13,96\end{array}$} & \multirow{2}{*}{$\begin{array}{l}\text { SD } \\
0,35\end{array}$} & \\
\hline KG & middle school students, using the virtual laboratory & & & \\
\hline PG & middle school students, watching their teacher presentations & 14,00 & 0,29 & 25 \\
\hline FG & $\begin{array}{l}\text { middle school students, watching movies depicting the process of the } \\
\text { experiment }\end{array}$ & 13,96 & 0,20 & 25 \\
\hline KL & secondary school students, using the virtual laboratory & 17,00 & 0,00 & 25 \\
\hline PL & secondary school students, watching their teacher presentations & 17,08 & 0,28 & 25 \\
\hline FL & $\begin{array}{l}\text { secondary school students, watching movies depicting the process of } \\
\text { the experiment }\end{array}$ & 16,96 & 0,35 & 25 \\
\hline
\end{tabular}

\section{Instruments and Procedures}

The research used tests with multiple choice questions with a single answer mode. The questions in the pre-test, the post-test and the delayed post-test included the same range of topics. Each test consisted of 20 questions. The questions in the tests belonged to particular taxonomy categories with regard to the teaching goals. Five test questions were assigned to each category. The basis was the taxonomy of the teaching goals of B. Bloom (1956; Andreson \& Krathwohl, 2001), consisting of educational goal classification, which allowed a precise and unambiguous description of the tested student's ability. B. Niemierko, (1977) based on the taxonomy of B. Bloom, developed a taxonomy of Chemistry teaching goals. This taxonomy consisted of four main categories, namely: memorizing the information (A), understanding the information (B), using the information in an appropriate situation (C), and using the informa- 
Piotr JAGODZIŃSKI, Robert WOLSKI. The Examination of the Impact on Students' Use of Gestures while Working in a Virtual Chemical Laboratory for their Cognitive Abilities

OF EDUCAT

IN THE $21^{\text {st }}$ CENTURY Volume 61, 2014

tion in a similarly difficult situation (D). Following these categories, appropriate questions were selected from a ready set of standardized Chemistry questions in tests for students of middle school and secondary school. For each correct answer, the student got 1 point and for each incorrect answer, the student got 0 points. Every student in the test could have scored 20 points. A diagnostic survey, according to the Likert scale survey (Likert, 1932; Gamst, 2008), was also implemented. The survey consisted of 10 questions. The survey questions are as follows:

1. Did your work in a virtual laboratory affect the increase in your commitment to the work in a real lab?

2. Are you more willing to work in a real lab when you have practiced before performing experiments in a virtual lab?

3. Did your work in a virtual lab help to make your work in a real lab more efficient by decreasing the time required to perform the experiments?

4. Did your work in a virtual lab help to make your work in a real lab more efficient by decreasing the number of mistakes made while performing an experiment?

5. Did the result of your work in a virtual laboratory have an impact on encouraging you to verify them in a real lab?

6. Thanks to your work in the virtual lab, would you willingly carry out more experiments in a real laboratory than according to the projected schedule?

7. Thanks to your work in the virtual lab, can you easily design new chemical experiments?

8. Did your thoughts about the work in the virtual laboratory affect your level of confidence when performing laboratory activities in a real lab?

9. Has your work in the virtual lab strengthened your confidence in performing experiments with a positive outcome in a real lab?

10. Has your work in the virtual lab increased your confidence in the growth of the work's effectiveness in relation to the performance of the manual tasks in a real laboratory?

The scale of the answers available in the survey:

1. Strongly disagree, 2. Disagree, 3. Neither agree nor disagree, 4. Agree, 5. Strongly agree.

The survey was carried out among students working with a virtual lab in order to examine the students' opinion on the use of the virtual laboratory system when supported by the gesture recognition system in teaching Chemistry. The survey results were to provide answers to the questions involving the intensity of the student's emotional involvement in laboratory work and the changes in the student's sense of self-efficiency in laboratory work.

\section{Data Analysis}

The research determined the growth and sustainability of the information among students and the educational effectiveness of the teaching measures. The determination of these results was based on the points earned in various tests (Jagodziński \& Wolski, 2012). The information increase among students from particular groups was determined by the difference between the results of the post-test and the pre-test. However, the students' information sustain- 
Piotr JAGODZIŃSKI, Robert WOLSKI. The Examination of the Impact on Students' Use of Gestures while Working in a Virtual Chemical Laboratory for their Cognitive Abilities

ability was determined by the difference between the post-test results and the delayed post-test. On the other hand, the effectiveness in education of the virtual laboratory in teaching Chemis-

PROBLEMS

OF EDUCATION

IN THE $21^{\text {st }}$ CENTURY

Volume 61,2014

try was determined by the difference between the increase in information that was gained by students working with the virtual lab, when set against the increase in information gained by students from the other groups. The results were statistically analyzed in order to determine the statistical significance difference of the result. For this purpose, the one-way analysis of variance (ANOVA) was used, where the assumed level of significance is $\alpha=0.05$. For this was used STATISTICA 10 software (Statistica, nd.).

In the survey, students could only choose one possible answer for each question. The answers to all the questions given to the students were studied. The results were presented in percentages.

\section{Results of the Research}

The following tables below present the summary of the calculated results of the study.

Table 2. Results about the increase in knowledge, effectiveness of an educational virtual laboratory and the durability of information, achieved by appropriate groups of middle school students (\%).

\begin{tabular}{|c|c|c|c|c|c|}
\hline & \multicolumn{5}{|c|}{ Taxonomy learning objective categories } \\
\hline & A & B & C & $\mathrm{D}$ & G (generally) \\
\hline Group symbol & \multicolumn{5}{|c|}{ Increase in student knowledge } \\
\hline KG & $216^{*}$ & $242^{*}$ & $304^{*}$ & $291^{*}$ & $256^{*}$ \\
\hline FG & $138^{*}$ & $135^{*}$ & $200^{*}$ & $172^{*}$ & $156^{*}$ \\
\hline \multirow[t]{2}{*}{ PG } & $149^{*}$ & $145^{*}$ & $208^{*}$ & $188^{*}$ & $166^{*}$ \\
\hline & \multicolumn{5}{|c|}{$\begin{array}{l}\text { The determined effectiveness of an educational virtual laboratory in relation to other } \\
\text { teaching aids }\end{array}$} \\
\hline KG-PG & 45 & $67^{*}$ & 46 & $55^{*}$ & $54^{*}$ \\
\hline \multirow[t]{2}{*}{ KG-FG } & $56^{*}$ & $79^{*}$ & $52^{*}$ & $69^{*}$ & $64^{*}$ \\
\hline & \multicolumn{5}{|c|}{ The determined durability of student knowledge } \\
\hline KG & $89^{*}$ & $89^{*}$ & $87^{*}$ & $88^{*}$ & $88^{*}$ \\
\hline FG & $82^{*}$ & $80^{*}$ & $71^{*}$ & $74^{*}$ & $77^{*}$ \\
\hline PG & $84^{*}$ & $85^{*}$ & $75^{*}$ & $75^{*}$ & $81^{*}$ \\
\hline
\end{tabular}

Note: The sign $(*)$ indicates statistically significant results, determined from the ANOVA. 
Piotr JAGODZIŃSKI, Robert WOLSKI. The Examination of the Impact on Students' Use of Gestures while Working in a Virtual Chemical Laboratory for their Cognitive Abilities

PROBLEMS OF EDUCATION IN THE $21^{\text {st }}$ CENTURY Volume 61, 2014

Table 3. Results about the increase in knowledge, effectiveness of an educational virtual laboratory and the durability of information, achieved by appropriate groups of secondary school students (\%).

\begin{tabular}{|c|c|c|c|c|c|}
\hline & \multicolumn{5}{|c|}{ Taxonomy learning objective categories } \\
\hline & $A$ & $\mathrm{~B}$ & C & $\mathrm{D}$ & G (generally) \\
\hline Group symbol & \multicolumn{5}{|c|}{ Increase in student knowledge } \\
\hline $\mathrm{KL}$ & $109^{*}$ & $116^{*}$ & $124^{*}$ & $165^{*}$ & $125^{*}$ \\
\hline FL & $72^{*}$ & $72^{*}$ & $83^{*}$ & $100^{*}$ & $80^{*}$ \\
\hline \multirow[t]{2}{*}{ PL } & $92^{*}$ & $102^{*}$ & $85^{*}$ & $108^{*}$ & $96^{*}$ \\
\hline & \multicolumn{5}{|c|}{$\begin{array}{l}\text { The determined effectiveness of an educational virtual laboratory in relation to other } \\
\text { teaching aids }\end{array}$} \\
\hline KL-PL & 19 & 14 & 46 & $53^{*}$ & $31^{*}$ \\
\hline \multirow[t]{2}{*}{ KL-FL } & $51^{*}$ & $61^{*}$ & $51^{*}$ & $65^{*}$ & $57^{*}$ \\
\hline & \multicolumn{5}{|c|}{ The determined durability of student knowledge } \\
\hline KL & $85^{*}$ & $88^{*}$ & 93 & 92 & $89^{*}$ \\
\hline FL & $71^{*}$ & $66^{*}$ & $68^{*}$ & $59^{*}$ & $67^{*}$ \\
\hline PL & $78^{*}$ & $74^{*}$ & $76^{*}$ & $67^{*}$ & $74^{*}$ \\
\hline
\end{tabular}

Note: The sign $\left(^{*}\right)$ indicates statistically significant results, determined from the ANOVA.

Table 4. The results of the diagnostic survey.

\begin{tabular}{|c|c|c|c|c|c|c|c|c|c|c|}
\hline \multirow{3}{*}{ Questions } & \multicolumn{10}{|c|}{ Answers [\%] } \\
\hline & \multicolumn{2}{|l|}{$1^{*}$} & \multicolumn{2}{|l|}{$2^{*}$} & \multicolumn{2}{|l|}{$3^{*}$} & \multicolumn{2}{|l|}{$4^{*}$} & \multicolumn{2}{|l|}{$5^{*}$} \\
\hline & G & L & G & $\mathrm{L}$ & G & $\mathrm{L}$ & G & L & G & L \\
\hline 1. & 0 & 0 & 0 & 0 & 3 & 7 & 19 & 15 & 79 & 79 \\
\hline 2. & 0 & 0 & 3 & 3 & 5 & 8 & 23 & 31 & 70 & 59 \\
\hline 3. & 0 & 0 & 0 & 0 & 7 & 15 & 12 & 19 & 81 & 67 \\
\hline 4. & 3 & 4 & 1 & 3 & 0 & 3 & 28 & 33 & 68 & 58 \\
\hline 5. & 0 & 0 & 0 & 0 & 1 & 7 & 35 & 47 & 64 & 47 \\
\hline 6. & 3 & 9 & 0 & 1 & 7 & 11 & 29 & 36 & 62 & 43 \\
\hline 7. & 7 & 11 & 12 & 15 & 11 & 15 & 37 & 41 & 33 & 19 \\
\hline 8. & 0 & 0 & 0 & 0 & 3 & 8 & 13 & 21 & 84 & 71 \\
\hline 9. & 0 & 0 & 1 & 3 & 13 & 19 & 31 & 38 & 55 & 41 \\
\hline 10. & 0 & 0 & 4 & 5 & 12 & 17 & 29 & 35 & 55 & 43 \\
\hline
\end{tabular}

Note: Answers - 1. Strongly disagree, 2. Disagree, 3. Neither agree nor disagree, 4. Agree, 5. Strongly agree; $\mathrm{G}$ - middle school, $\mathrm{L}$ - secondary school. 


\section{Discussion}

For the middle school students, after the research was completed, there was a substantial increase in their gained information, in some cases, up to $200 \%$. Two factors contributed to this phenomenon. First of all, this increase was caused by a low level of Chemistry familiarity at the beginning of the research. Secondly, in the adopted methodology for calculation, the basis for the results was obtained by the students in the pre-test. Therefore, the increase in information gained by the secondary school students is more than twice lower than for the middle school students. Therefore, the increase of information gained on the secondary school students is more than twice lower than that for the middle school students. This is due to the higher level of information attained by the secondary school students at the beginning of the research.

The use of a virtual laboratory, which is based on a system of gestures (GBS), on secondary school students, resulted in an increase in the understanding of information in relation to the group of students working with movie instructions and the group of students watching their teacher presentations. This increase was due to the use of gestures and movements by students while performing experiments in a virtual lab. In contrast, the group of students who watched movies or their teacher presentations did not perform gestures, but only watched them. For the middle school students, who were working with a virtual laboratory, better results in terms of understanding the information (B) had further consequences in the form of a better performance by them in terms of problem solving $(\mathrm{C})$, requiring a good understanding of information and creative thinking (D) (Table 2). In the case of secondary school students, the efficacy results of the educational virtual laboratory shaped differently than in the case of the middle school students (Table 3). This is due to the knowledge resource these students have acquired while studying Chemistry at the middle school. In the case of the secondary school students who were working with a virtual lab and the students watching their teacher presentation, there was no significant difference on the basis of the first two taxonomy categories in educational objectives, that is remembering the information (A) and understanding the information (B), because, in both cases the involvement of students in the observations of the course of the experiments is similar. Watching movies on the course with the experiments is associated with less student involvement, as the video only shows the normal course of the experiment, and the students just see the gestures and movements of the experimenter. In this case, remembering and understanding the information is weaker. However, in the case of both secondary school student groups, seeing their teacher presentations and working with movie instructions, there is no trend observed for the ability to use information in a typical situation $(\mathrm{C})$, and in resolving the problems (D). Working with a virtual laboratory positively affects the durability of the information for the middle school students, because the manual activities that the students independently perform while working with it, force them to a greater attention and perception. It affects a greater degree of assimilation and understanding the information (A, B), which translates into problem-solving skills $(\mathrm{C}, \mathrm{D})$. This beneficial effect of working with a virtual laboratory for the durability of information was also observed in the case of the secondary school students. In this case, in addition to a greater concentration and perception of the students, an additional factor in the considerable durability of the information was the previously acquired knowledge while studying Chemistry at the middle school.

The results of the survey (Table 4) confirm the usefulness of a virtual chemical laboratory, which is using a system of gestures and movements in Chemistry education. Students from the study groups who were working with a virtual laboratory confirmed that this increased their commitment to work in a real lab. In the majority of the surveyed students, there was an increased willingness to work in a school Chemistry laboratory as well as an increased interest in the Chemistry subject. The students also felt the increased efficiency of their work, because they could carry out experiments in a shorter time, committing fewer errors. The positive ex- 
Piotr JAGODZIŃSKI, Robert WOLSKI. The Examination of the Impact on Students' Use of Gestures while Working in a Virtual Chemical Laboratory for their Cognitive Abilities

OF EDUC

PROBLEMS

IN THE $21^{\text {st }}$ CENTURY

Volume 61, 2014

periment results, obtained from the students while working in a virtual laboratory, encourage the students to repeat them in a real laboratory. Due to the work in the virtual laboratory, this has increased student ability to solve problems in a laboratory that confirms the results obtained by them in the activities corresponding to category D in the taxonomy of learning objectives. The survey results also indicate that the students have mastered laboratory activities, which increased their belief that they will now perform more experiments with positive results. The students emphasized that training in a virtual lab increased their sense of effectiveness of their work in a real lab.

However, following on from our observations, at the beginning of the students' work with the virtual lab, they ran into some difficulties when the teaching measure being used was not well known to them. This consisted of the fact that they had to be fully capable of performing certain gestures that were appropriate for the experiment that they were going through. It was something new to the students, as well as there being some kind of difficulty in getting used to making gestures and movements in the air, as well as imitating certain laboratory activities, but without touching actual objects. An additional complication arose from the technical equipment going through some slight delay in the processing by the Kinect sensor gestures and movements. In addition, a further disadvantage is the need to stand in front of the Kinect sensor while working in the virtual laboratory. Comparing the described virtual lab with already existing similar virtual laboratories (Chemistry labs, nd.) and using such interfaces as a mouse and a keyboard, we can see that the use of Kinect has brought the quality of students' work closer to working in real conditions. Using this type of interface has created the opportunity to prepare a new generation of virtual labs.

\section{Conclusions}

Analyzing the obtained results shows that the use of the gesture recognition system when using Kinect in the virtual lab had a positive impact on increasing the efficiency of teaching Chemistry. Students working with a virtual lab gave a better performance in terms of remembering information, and also showed the greater durability of remembering information. To a greater extent, students could understand the information passed to them. Moreover, it increased their ability to use the knowledge acquired in solving tasks in situations known to them from lessons. As a result, they achieved even better results in solving problematic laboratory tasks, which is related to achieving the objectives contained in the taxonomy category of learning objectives with the highest educational value. Comparing the achievements of students of particular middle and secondary school groups, we can conclude that the use of gestures and movements in a virtual chemistry laboratory offers higher efficiency than education for students from the other groups. The use of a Kinect sensor recognizing gestures and movements can increase the interactivity and effectiveness of an educational virtual laboratory. The inclusion of human movements in the cognitive process makes learning that is supported by multimedia content by using gestures produce better results and is more effective, which confirms the assumptions embodied in the cognition theories. Indeed, in our study, groups of students who were working with a virtual laboratory, using gestures and hand movements, achieved the best results. Students from other groups watching their teacher presentations and movie instructions, which did not use these gestures, achieved worse results, especially in solving problems. The results of our research regarding the application of the gesture and movement recognition system in the virtual Chemistry lab showed that gesture recognition computer technology will make a big impact on education in the future. The virtual laboratory we have developed with the Kinect sensor, in our opinion, is the new path to virtualization different laboratories doing very similar operations manually in a virtual environment to those in a real environment. The statements of the students who were surveyed show that the support of the GBS system of 
Piotr JAGODZIŃSKI, Robert WOLSKI. The Examination of the Impact on Students' Use of Gestures while Working in a Virtual Chemical Laboratory for their Cognitive Abilities

educational software enhances its attractiveness and emotional involvement. All these factors increase students' self-efficiency and self-confidence while working in the laboratory.

$\mid$\begin{tabular}{l} 
PROBLEMS \\
OF EDUCATION \\
IN THE 21 $1^{\text {st }}$ CENTURY \\
Volume 61, 2014 \\
\hline 55
\end{tabular}

\section{Acknowledgments}

The authors acknowledge the support of the Ministry of Education, Science and Sport of Republic of Slovenia and European Social Fund in the frame of Project: "Innovative pedagogy 1: 1 in the light of competences of the 21st century" on Faculty of Natural Sciences of University of Maribor
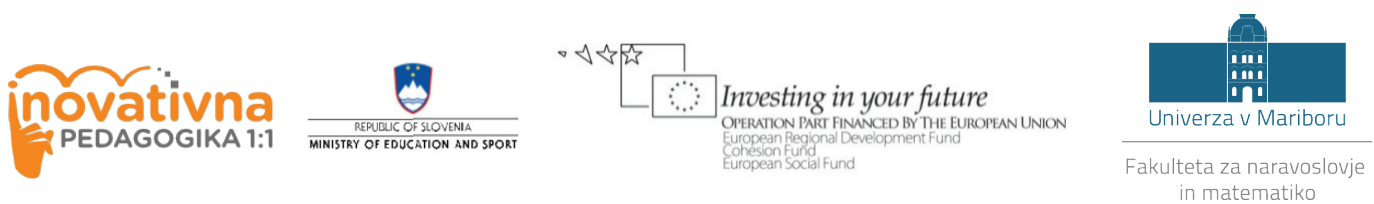

\section{References}

Andreson, L. W., Krathwohl, D. R. (2001). A taxonomy for learning, teaching and assessing: A revision of Bloom's taxonomy. Longman Publishing, NY.

Ayas, A., Cepni, S., \& Akdeniz, A. R. (1994). Importance of laboratory in science education-II. Journal of Contemporary Education Research and Innovation, 205, 7-11.

Ayres, P., Marcus, N., Chan, C., \& Qian, N. X. (2009). Learning hand manipulative tasks: When instructional animations are superior to equivalent static representations. Computers in Human Behavior, 25 (2), 348-353

Barsalou, L. W. (1999). Perceptual symbol system. Behavioral and Brain Sciences, 22, 577-660.

Barsalou, L. W. (2008). Grounded cognition. Annual Review of Psychology, 59 (1), 617-645.

Bílek, M. (2010). Natural science education in the time of virtual worlds. Journal of Baltic Science Education, 9 (1), 4-5.

Bloom, B. S., Engelhart, M. D., Furst, E. J., Hill, W. H., Kratwohl, D. R. (1956). Taxonomy of educational objectives. The classification of educational goals. Handbook 1: Cognitive domain. David McKay, NY.

Bozdogan, A. E., Yalcin, N. (2004). The rate of experiments being carried out in science lessons at elementary education and the problems encountered during the physics experiments. Journal of Kirsehir Education Faculty, 5, 59-70.

Calik, M. (2013). Effect of technology-embedded scientific inquiry on senior science student teachers' self-efficacy. Eurasia Journal of Mathematics, Science and Technology Education, 9 (3), 223232.

Chang, Ch., Chen, Y., Chiang, Ch., Lin, M., Lai, H. (2013). Embodying gesture-based multimedia to improve learning. British Journal of Educational Technology, 44 (1), E5-E9.

Chemical experiment. (2008). Retrieved from http://www.eksperymentychemiczne.pl

Chemistry labs. (nd.). Retrieved from http://onlinelabs.in/chemistry

Cohen, L., Manion, L., Morrison, K. (2011). Research methods in education, Routledge, NY.

Czupiał, K., Niemierko, B. (1977). Methodology of chemical test. WSiP, Warszawa.

De Grove, F., Van Looy, J., Neys, J., Jansz, J. (2012). Playing in school or at home. An exploration of the effects of context on educational game experience. Electronic Journal of e-Learning, 10 (2), $185-198$

de Koning, B. B., \& Tabbers, H. K. (2011). Facilitating understanding of movements in dynamic visualizations: An embodied perspective. Educational Psychology Review, 23 (4), 501-521.

Dede, C. J., Salzman, M., Loftin, R. B. (1996). The development of a virtual world for learning new Newtonian mechanics on high school students. In: Multimedia, hypermedia and virtual reality: Models, systems, and applications, Vol. 1077, Springer-Verlag, Berlin, pp. 87-106.

Ebenezer, J., Columbus, R., Kaya, O. N., Zhang, L., Ebenezer, D. L. (2012). One science teacher's professional development experience: A case study exploring changes in students' perceptions on their fluency with innovative technologies. Journal of Research in Science Teaching, 21 (1), 22-37. 
Piotr JAGODZIŃSKI, Robert WOLSKI. The Examination of the Impact on Students' Use of Gestures while Working in a Virtual Chemical Laboratory for their Cognitive Abilities

PROBLEMS

OF EDUCATION

IN THE $21^{\text {st }}$ CENTURY Volume 61,2014

56

Ebenezer, J. V., Kaya, O. N., Ebenezer, D. L. (2011). Engaging students in environmental research projects: Perceptions of fluency with innovative technologies and levels of scientific inquiry abilities. Journal of Research in Science Teaching, 48 (1), 94-116.

Gamst, G., Meyers, L. S., Guarino, A. J. (2008). Analysis of variance designs. A conceptual and computational approach with SPSS and SAS. Cambridge University Press, NY, pp. 10.

Jagodziński, P., Wolski, R. (2012). Assessing the educational effectiveness of film of chemical experiments for educating deaf-mute junior high and high school students. Journal of Chemical Education, 89, 1122-1127, doi:10.1021/ed101052w.

Jagodziński, P., Wolski, R. (2012). Research into the educational effectiveness of a web-based textbook in the teaching of chemical experimentation. Journal of Science Education, 1, 13, 9-12.

Johnson, L., Smith, R., Willis, H., Levine, A., \& Haywood, K. (2011). The 2011 horizon report. Austin, TX: The New Media Consortium.

Josephsen, J., \& Kosminska-Kristiansen, A. (2006). Simulation of laboratory assignments to support students' learning of introductory inorganic chemistry. Chemistry Education Research and Practice, 7 (4), 266-279

Krajcik, J. S. (2002). The value and challenges of using learning technologies to support students in learning science. Research in Science Education, 32, 411-414.

Lamanuskas, V. (2011). Digital education: Some implication. Journal of Baltic Science Education, 10 (4), 216-218.

Likert, R. (1932). A technique for the measurement of attitudes. Archives of Psychology, 140, 55.

Liu, H., \& Su, I. (2011). Learning residential electrical wiring through computer simulation: The impact of computer-based learning environments on student achievement and cognitive load. British Journal of Educational Technology, 42 (4), 598-607.

Macedonia, M., Müller, K., \& Friederici, A. D. (2010). The impact of iconic gestures on foreign language word learning and its neural substrate. Human Brain Mapping, 32, 982-998.

Machková, V., Bílek, M. (2013). Didactic analysis of the web acid-base titration simulations applied in pre-graduate chemistry teachers education. Journal of Baltic Science Education, 12 (6), 829839.

Millar, R. (2004). The role of practical work in the teaching and learning science. High School Science Laboratories: Role and Vision. National Academy of Science, Washington DC.

Murphy, S. (2012). Design considerations for a natural user interface (NUI). Texas Instruments Incorporated, Dallas, TX, Retrieved March 11, 2014, from http://www.ti.com/lit/wp/spry181/spry181. pdf.

Odubunni, T., Balagun, A. (1991). The effect of laboratory and lecture teaching methods on cognitive achievement in integrated science. Journal of Research in Science Teaching, 28, 213-224.

Pekdag, B. (2010). Chemistry learning alternative routes: animation, simulation, video, multimedia. Journal of Turkish Science Education, 7, 79-110.

Prinz, J. J. (2002). Furnishing the mind: Concepts and their perceptual basis. Cambridge MA: MIT Press.

Sanger, M. J., Greenbowe, T. J. (2000). Addressing student misconceptions concerning electron flow in aqueous solutions with instruction including computer animations and conceptual change strategies. International Journal of Science Education, 22, 521-537.

Statistica, Retrieved August 24, 2014, from http://www.statsoft.com/Products/STATISTICA-Features

Stieff, M., Wilensky, U. (2003). Connected chemistry-incorporating interactive simulations into the chemistry classroom. Journal of Science Education and Technology, 12 (3), 285-302.

Svec, M. T., Anderson, H. (1995). Effect of microcomputer based laboratory on students graphing interpretation skills and conceptual understanding of motion. Dissertation Abstract International, 55 (8), 23-38.

Tatli, Z. H. (2009). Computer based education: Online learning and teaching facilities. Energy Education Science and Technology, Part B 1, 171-181.

Wilson, M. (2002). Six views of embodied cognition. Psychonomic Bulletin \& Review, 9, 625-636.

Wong, A., Marcus, N., Ayres, P., Smith, L., Cooper, G. A., Paas, F. (2009). Instructional animations can be superior to statics when learning human motor skills. Computers in Human Behavior, 25 (2), 339-347. 
Piotr JAGODZIŃSKI, Robert WOLSKI. The Examination of the Impact on Students' Use of Gestures while Working in a Virtual Chemical Laboratory for their Cognitive Abilities

Xie, Y., Reider, D. (2013). Integration of innovative technologies for enhancing students' motivation for science learning and career. Journal of Science Education and Technology, doi:10.1007/s10956013-9469-1.

Yang, K. Y., Heh, J. S. (2007). The impact of internet virtual physics laboratory instruction on the achievement in physics, science process skills and computer attitudes of 10th grade students. Journal of Science Education and Technology, 16, 451-461.

Zhang, L. (2013). A meta-analysis method to advance design of technology-based learning tool: Combining qualitative and quantitative research to understand learning in relation to different technology features. Journal of Science Education and Technology, doi:10.1007/s10956-013-9460-x.

Advised by Boris Aberšek, University of Maribor, Slovenia

Received: July 25, 2014

Accepted: August 28, 2014

Piotr Jagodziński

Ph.D., Assistant Professor, Adam Mickiewicz University, Faculty of Chemistry, Department of Chemical Education, Umultowska 89b, 61-614 Poznań, Poland. E-mail: piotrjot@amu.edu.pl

\section{Robert Wolski}

(Corresponding author)
Ph.D., Assistant Professor, Adam Mickiewicz University, Faculty of Chemistry, Department of Chemical Education, Umultowska 89b, 61-614 Poznań, Poland. E-mail:wola@amu.edu.pl $\mid$\begin{tabular}{l} 
PROBLEMS \\
OF EDUCATION \\
IN THE 21 $1^{\text {st }}$ CENTURY \\
Volume 61, 2014 \\
\hline 57
\end{tabular} 